\title{
A GEOGRAFIA FENOMENOLÓGICA DE MACHADO DE ASSIS
}

\author{
Marquessuel Dantas de Souza* \\ * Graduado em Geografia. Faculdade de São Paulo. São Paulo-SP. Estudante do Grupo de Pesquisa Geografia, Literatura e Arte (Geoliterart) \\ da USP. E-mail: marquessuelgf@gmail.com.
}

Recebido em 11/2014. Aceito para publicação em 01/2015.

Versão online publicada em 13/01/2016 (http://seer.ufrgs.br/paraonde)

\begin{abstract}
Resumo: No presente texto busca-se fazer uma breve análise da Geografia Fenomenológica presente nos escritos de Machado de Assis. Procura-se evidenciar, igualmente, a possibilidade de uma leitura da paisagem da cidade do Rio de Janeiro do século XIX, bem como intenta-se mostrar a ideia de lugar e de espaço na trama machadiana. Estes conceitos tornam-se fundamentais no âmbito da Geografia; entrementes, permitem identificar um Machado de Assis como um imanente geógrafo urbano. Muito embora a paisagem, o lugar e o espaço possam transcender os personagens em seus relacionamentos citadinos do cotidiano, vê-se uma geograficidade de fundo permeando as tramas machadianas.
\end{abstract}

Palavras-chave: Geografia; Machado de Assis; Fenomenologia.

\section{Introdução}

Machado de Assis, teu nome vale o século em que viveu, teu nome equivale ao século XIX na cidade do Rio de Janeiro. Tua marca está registrada em seus escritos que, cujos mesmos podem-se dizer escritos magistrais para com a cultura brasileira. Neste sentido, o mesmo é válido, por exemplo, para José de Alencar ${ }^{1}$, com sua virtuosidade literária no qual aborda, através de seus escritos, em especial os romances, tanto aspectos rurais (interioranos, sertanejos) quanto urbanos (citadinos litorâneos/costeiros); o mesmo diz-se de Mario de Andrade, principalmente quando da contribuição de sua crítica literária e de sua crítica para com a música brasileira $^{2}$. Entretanto, se faz um direcionamento aos escritos de Machado de Assis, haja vista ser a proposta na temática deste texto. Em realidade, Machado de Assis traduz nas entrelinhas de seus escritos uma geografia imanente que poucos literatos, ou melhor, poucos críticos de arte conseguiram enxergar. Muito embora o próprio Machado não tenha demonstrado interesse em promover um discurso de cunho geográfico em seus textos. Neste contexto, identifica-se decerto que Machado de Assis não se preocupou em descrever, rigorosamente, a paisagem do Rio de Janeiro. Muito embora, seus escritos nos deixem impressões riquíssimas - esteticamente - sobre o tema. Isto é válido também para a ideia de lugar e de espaço traçados nas tramas machadianas.

A geografia contida nos textos machadianos nos mostra, por assim dizer, uma cidade (Rio de Janeiro) num contexto importante na política, na economia, em suma, na cultura do Brasil em transição; do fim do período imperial. Além disso, é notável lembrarmos que a maioria das tramas dos textos machadianos se passa no âmbito urbano, ou seja, apresentam-se como um diagnóstico ou, podemos considerar um itinerário de geografia urbana. Há pouca descrição do meio rural. A bem dizer, quase toda a obra machadiana se passa no ambiente urbano: característica sua, homem citadino, um burguês carioca. Não obstante, esta geografia demonstra um envolvimento fenomenológico (ontológico) entre os personagens, o autor-escritor e a realidade empírica da cidade do Rio de Janeiro do século XIX.

O presente texto nos conduz para um olhar sobre a geograficidade da cidade do Rio de Janeiro do século XIX. Os romances e os contos são as peças centrais onde o cenário carioca acontece. 0 elemento estético-pictórico no que diz respeito ao espaço de vivência contribui

\footnotetext{
${ }^{1}$ Escritor regionalista, José de Alencar merece ser chamado aqui de Geógrafo. Entre suas principais obras encontram-se os romances urbanos Lucíola (1862), Diva (1864) e Senhora (1875); romances sertanejos tais como O Gaúcho (1870), O Tronco de Ipê (1872), 0 Sertanejo (1875), apenas para citar alguns.

${ }^{2}$ É oportuno dizer o mesmo - assim consideramos -, de Adoniran Barbosa. Exímio compositor e do mesmo modo, um excelente geógrafo. No entanto, apesar de se enveredar pela literatura musicada, não deixa de ter importância para com os estudos geográficos. Adoniran em quase todas as suas músicas descreve a cidade de São Paulo de forma simples, por sua vez, singular. Suas canções evidenciam as transformações que a cidade enfrenta na época que as compôs. A industrialização e a urbanização são os temas centrais de sua crítica da cidade-residência. - Em realidade o samba adonirano é um verdadeiro roteiro da geografia paulistana do século XX. Decerto, uma geografia urbana musicada.
} 
significativamente para descobrirmos um Brasil que já não é mais o mesmo da época em que viveu o escritor Machado de Assis. Porém, há muita coisa preservada em relação à geografia carioca. No que concerne à geografia fenomenológica machadiana, as páginas a seguir se insere numa espécie de interlúdio literário para com a obra do assim considerado, o mais eminente e maior escritor do Brasil: Machado de Assis.

\section{Machado de Assis como geógrafo: um prelúdio}

"A dialética entre Geografia e Literatura é fundamental para compreendermos a relação do ser ou criador artístico com a experiência da narrativa dos lugares" ${ }^{3}$. Ao efetuar um estudo relacionando dois campos do saber, verifica-se a complexidade em tratar o assunto. Contudo, vê-se o enriquecimento por ter dois modos de se ler ou de decifrar o mundo. Assim, os estudos geográficos por meio da literatura nos possibilita entendermos o passado a fim de que possamos compreender o presente e, por conseguinte, o futuro.

Transformações sócio-espaciais fecunda e potencialmente evidentes, o olhar geográfico na interioridade da obra literária traduz a percepção que o geógrafo tem do mundo circundante, assim como do autor literato e do próprio personagem da trama, seja dos romances, contos ou poemas. Por sua vez, Machado de Assis por meio de seus escritos nos deixa a impressão de uma singular participação quando de suas descrições referentes à geografia urbana carioca. Para tanto, pode-se dizer que pensar a grafia brasileira é pensar a cultura histórico-geográfica do Brasil. - Os passeios relatados nas tramas nas quais muitas se passam pelas ruas do centro da cidade bem como de áreas afastadas da região central, os relatos de acontecimentos semelhantes são descrições que permeiam toda a literatura dos romances machadianos, conquanto constituem-se detalhes fundamentais para identificar a geografia e a historiografia machadiana.

Identificamos que na maioria dos romances e contos machadianos há uma intenção geográfica. Machado de Assis fora um verdadeiro paisagista brasileiro, ele percebeu a natureza da Guanabara de forma singular. Ele a descreveu sutilmente. Bem entendido, pode-se dizer ser "Machado de Assis, pintor da natureza e paisagista" ${ }^{4}$. Em realidade, um geógrafo imanente.

Neste contexto, pode-se considerar "Machado de
Assis um dos maiores paisagistas brasileiros" ${ }^{5}$. De fato, Machado além de descrever a paisagem, ele descreve o lugar e o espaço, bem como também descreve a vida carioca. Destarte, o olho machadiano vê o Rio de Janeiro se deslumbrar diante da própria natureza. A narrativa machadiana consegue, por assim dizer, fazer com que o geógrafo que tenha lido suas obras tenha em mente uma real noção daquilo que seus escritos apresentam. Os caminhos que se cortam na paisagem carioca nos escritos machadianos nos faz identificar, grosso modo, um "geógrafo aprendiz que fora Machado de Assis"6. Desvelando o espaço geográfico singularmente, algo que muitos geógrafos não conseguem realizar ou acompanhar.

A presença de ruas e praças do centro velho da cidade do Rio de Janeiro, assim como dos morros, nos romances de Machado de Assis, é elucidativa de como esses espaços, a partir do momento que articulam vivências e experiências, ao mesmo tempo em que passam a ser dotados de valor e sentimentos, tornam-se lugares na narrativa machadiana. Espaço urbano esse que sofreu inúmeras intervenções a cada uma das fases de crescimento da cidade e que teve como resultado a criação de ruas e praças que hoje fazem parte da paisagem da cidade do Rio de Janeiro ${ }^{7}$.

A estética pitoresco-descritiva de alguns bairros do Rio de Janeiro evocada por Machado de Assis transmite, ou melhor, traduz que o próprio autor dos textos exercia uma preocupação com os pormenores de seu meio. Através das palavras machadianas é permitido afirmar sua sensibilidade para com a cidade que concentrava quase toda a riqueza do império, ou como queiram do território (pois o Rio de Janeiro à época era a capital do império). - A natureza está em toda parte. Neste sentido, os textos machadianos nos demonstram sensivelmente que "a geografia está em toda parte", conforme ilustra suas impressões.

A relação homem-meio parece mais "uma espécie de participação mística do humano com o telúrico" contudo, isso não é uma aparência, mais sim uma realidade existencial efetiva e que está presente nas tramas machadianas. A natureza, talvez possa parecer ausente de uma tela ou de uma narrativa, porém, permanece "estando na realidade estranhamente presente" ${ }^{10}$. A

\footnotetext{
${ }^{3}$ SOUZA, Marquessuel Dantas de. Geografia e Cultura: o espaço em prosa, mapa literário e imaginação. 2013a, p. 244. In: RA’E GA. Acesso em 11 de junho 2013.

${ }^{4}$ BASTIDE, Roger. Machado de Assis, paisagista. 2002-2003, p. 193. In: Revista USP. Acesso em 09 de setembro de 2013.

${ }^{5}$ Ibidem, p. 193.

${ }^{6}$ SOUZA, Marquessuel Dantas de. Uma leitura da paisagem em Brás cubas e Quincas Borba de Machado de Assis: um olhar estético-geográfico sobre o Rio de Janeiro do século XIX. (Grifo do autor). 2014, p. 31. In: Linguagens. Acesso em 26 de maio de 2014.

${ }^{7}$ BARCELLOS, Frederico Roza. Espaço, Lugar e Literatura: o olhar geográfico machadiano sobre a cidade do Rio de Janeiro. 2009, p. 48. In: Espaço e Cultura. Acesso em 25 de junho de 2012.

${ }^{8}$ COSGROVE, Denis. A geografia está em toda parte: cultura e simbolismo nas paisagens humanas. In: CORRÊA, Roberto Lobato e ROSENDAHL, Zeny (Orgs). Paisagem, Tempo e Cultura. 1998, p. 93.

${ }^{9}$ BASTIDE, Roger. Machado de Assis, paisagista. 2002-2003, p. 198. In: Revista USP. Acesso em 09 de setembro de 2013.

${ }^{10}$ Ibidem, p. 198.
} 
representação da vida social presente em Machado de Assis contribui, para aquilo que chamaremos 'espetáculo do ser-com', ou seja, uma fenomenologia do ser espacial (o homem) na relação com o ontológico transcendental (o além dele mesmo) no sentido heideggeriano. Uma questão ou ação metafísica, no sentido kantiano, e, ao mesmo tempo, realizando a transvaloração de todos os valores no sentido nietzschiano.

Os personagens machadianos aparecem sempre se relacionando, nunca isolados. Narrativa estética do jardim carioca, uma noção da dimensão espacial do autor dos romances, em especial. As impressões de Machado de Assis à literatura expressam seu verdadeiro espírito de escritor compromissado para com sua pátria. 0 mesmo busca "descobrir um meio de fazer a beleza carioca servir mais intimamente à beleza de seus romances"11. Além disso, "Machado de Assis realiza o milagre de tornar a natureza mais presente do que se a pintasse em longas páginas" ${ }^{12}$. Ele torna-se um verdadeiro autor místico paisagista. Conforme Bastide, para Machado de Assis, por exemplo, "o pedaço de praia entre a Glória e o Flamengo une com sua areia úmida, sua geografia oceânica e sentimental, a casa de Casmurro e a de Escobar" ${ }^{\prime 13}$. Neste contexto, percebese Machado de Assis um homem "citadino agarrado às ruas cariocas"14. Se se considerarmos sua afeição às ruas da cidade carioca percebe-se uma lógica de percepção espacial contido na busca por inscrever sua vivência da realidade que lhe pertence.

Nas palavras de Roger Bastide esse escritor foi "um dos maiores paisagistas do Brasil"15. Algo que já fora afirmado anteriormente. Em todo caso, na síntese de suas análises "o artifício da linguagem verbal transforma o texto literário em uma das possibilidades de expressão, representação e conhecimento da sociedade via a utilização das palavras (língua)"16.Com efeito, nos romances Memórias Póstumas de Brás Cubas e Quincas Borba, por exemplo, "as curtas descrições, muitas vezes resumidas em uma frase, têm importância desproporcional a sua extensão, pois ampliam a compreensão das personagens e sugerem nuanças sobre o significado dos acontecimentos" ${ }^{17}$. Bem entendido, a ideia de natureza (imanente) constante nas entrelinhas, cuja mesma é possível de se encontrar nos textos machadianos, nos oferece uma síntese de seu convívio em seu ambiente urbano. Neste sentido, o que os seus escritos exprimem são impressões do homem citadino. 0 homem que vive em meio aos materiais/construções e outros utensílios da cidade (além da concentração intelectual da Corte). Por vezes a imprensa e outros meios de divulgação em massa se concentravam na capital imperial, quer dizer, as melhores escolas, os melhores postos de saúde e de trabalho, as melhores instruções, entre outras coisas, se realizavam junto ao espaço onde a Corte estava. Fornecendo assim, melhores oportunidades àqueles que habitavam esse meio, por assim dizer, privilegiado. Uma vivência experimental do sujeito urbano, um indivíduo do meio político e que representa a sociedade da cidade grande. Algo comum no período do escritos machadianos, haja vista que isto também pode ser identificado em vários outros escritores do século XIX. Todavia, com ressalvas. José de Alencar, já referido, Lima Barreto, Graça Aranha, Aluísio de Azevedo dentre outros, são alguns dos exemplos para simplificar esta abordagem (autores que viviam nos meios urbanos das grandes cidades, de acordo com suas gerações).

A natureza, assim como a ideia de lugar e de espaço a "apelidamos de "paisagem"18. Para tanto, perceber a natureza nos faz enxergar a "Paisagem como obra de arte pictórica"19. Assim sendo, há a impressão de uma ideia mítica sobre o lugar, porém, o que se observa é a existência real agindo incessantemente. Contudo, a linguagem usada por Machado de Assis facilita a identificação da paisagem carioca do século XIX. Com efeito, uma paisagem urbana em geral. Por conseguinte, "as ruas, praças e morros são espaços que se transformam em lugares, os quais estão representados nos romances machadianos" 20 .

Em todo caso, "ao recorrermos ao texto literário podemos perceber que o espaço na obra machadiana se apresenta múltiplo, ora como espaço, ora como lugar, pois o escritor se fixava principalmente num trecho de rua, numa praça, num caminho, na praia ou na chácara" ${ }^{21}$. Bem entendido, "é preciso que a natureza seja uma personagem que represente o seu papel, que a paisagem tenha significação e finalidade próprias, que sirva para facilitar a compreensão dos homens ou auxiliar o desenrolar da ação, e não seja um mero quadro rígido" ${ }^{22}$. É com este intento que podemos identificar uma geografia nos escritos de Machado de Assis;

\footnotetext{
${ }^{11}$ Idem, p. 200.

12 Ibidem, p. 200.

${ }^{13}$ Idem, p. 201.

${ }^{14}$ Idem, p. 202.

${ }^{15}$ Ibidem, p. 202.

${ }^{16}$ ANTONELLO, Ideni Terezinha. O olhar geográfico na interioridade do olhar sensível da obra literária. 2005, p. 03. In: Simpósio Nacional sobre Geografia, Percepção e Cognição do Meio Ambiente. Acesso em 04 de agosto de 2012.

${ }^{17}$ SANTOS, Fabio Muruci dos. A Paisagem Oculta: desvelando o Rio de Janeiro do Quincas Borba de Machado de Assis. In: Revista Letras. Acesso em 22 de junho de 2013.

${ }^{18}$ SIMMEL, Georg. A Filosofia da Paisagem. 2009, p. 07. Disponível em: www.lusosofia.net. Acesso em 22 de junho de 2013.

${ }^{19}$ Idem, p. 08.

${ }^{20}$ BARCELLOS, Frederico Roza. Espaço, Lugar e Literatura: o olhar geográfico machadiano sobre a cidade do Rio de Janeiro. 2009, p. 49. In: Espaço e Cultura. Acesso em 25 de junho de 2012.

${ }^{21}$ Idem, p. 41.

${ }^{22}$ BASTIDE, Roger. Machado de Assis, paisagista. 2002-2003, p. 198. In: Revista USP. Acesso em 09 de setembro de 2013.
} 
em que paisagem, lugar e espaço aparecem amalgamados profundamente/intrinsecamente.

Diante desta exposição, engendra-se uma breve noção de metamorfose urbana. Ou dito de outra forma, percebe-se que a transformação da cidade do Rio de Janeiro é evidente na maioria dos textos do escritor carioca. A paisagem serve como ponto de referência ao sentido de localização, e isto é bem explícito nos escritos machadianos. Todavia, não podemos esquecer a ideia de temporalidade inscrita nos manuscritos do referido autor. Assim diz-se: uma conjuntura das múltiplas paisagens na unidade da natureza, em especial no Rio de Janeiro. Com isto pode-se dizer que Machado viu a geografia da própria vida ser modificada/alterada; já que nascera no Morro do Livramento e morrera no Cosme Velho, região central; não obstante, Machado de Assis viveu a 'Belle Époque' carioca.

\section{A Geografia em Memórias Póstumas de Brás Cubas (1881): um exemplo numa breve aborda- gem $^{23}$}

"As descrições paisagísticas contidas no Brás Cubas, por exemplo, nos fornece uma ideia ontológica por parte ao autor defunto" ${ }^{24}$. "Pois somos aquilo que viemos" ${ }^{25}$. Isto é, a época em que viveu o escritor Machado de Assis possibilitou que o mesmo descrevesse sua cidade como ela própria se apresentava diante seus olhos. Ou seja, aquilo que ele mesmo vivia (viveu). Portanto, é a partir deste cenário que o escritor encaminhará sua trama. 0 momento o envolve inexoravelmente. Isto, em toda a trama que se desenvolve de forma magnânima.

A primeira descrição da narrativa deste romance se passa exatamente quando dos primeiros dias de existência de Brás Cubas. Uma espécie de filosofia do ser é o que o autor defunto narra de sua história. Destarte, os contornos da cidade com seus ornamentos também são postos em linguagem simples. Brás Cubas nos confessa de seu primeiro encontro público nos conduzindo assim: "batizei-me na Igreja de São Domingos, uma terça-feira de março, dia claro, luminoso e puro" ${ }^{26}$.
Passados alguns anos, depois de estudar na Europa e agora de volta ao Rio na casa de campo, devido sua retirada logo após o falecimento de sua genitora, o Senhor Brás Cubas se expressa dizendo-nos: "sejamos simples, como era simples a vida que levei na Tijuca, durante as primeiras semanas depois da morte de minha mãe"27.

Bem entendido, devemos ressaltar que alguns acontecimentos marcam a narrativa desse romance humanista machadiano. Contudo, "não podemos nos esquecer de que Virgília e Lobo Neves são personagens importantes na trama do romance". Assim como o Quincas Borba. Entrementes, algumas passagens breves por todo o texto nos deixam uma rica impressão da vida citadina e como a cidade se apresenta com suas feições e suas variadas formas de mescla entre as pessoas que a habitam. - Em se tratando de Machado de Assis, devemos lembrar que ao recorrermos a um dos mestres de nossa literatura, constatamos que no âmbito de suas criações artísticas, buscamo-lo para mostrar como podemos "extrair valioso acervo geográfico que, se não substitui o trabalho profissional do geógrafo, enriquece-o sobremaneira, e pode auxiliá-lo" . Isto é válido também para qualquer outro escritor (do mesmo gênero literário, preferencialmente).

"A representação do espaço geográfico da cidade do Rio de Janeiro no final do século XIX" ${ }^{30}$ descrita por Machado de Assis numa passagem do romance, nos faz perceber sua sensibilidade singular perante a situação da vida urbana. Pois que, conforme o autor defunto (Brás Cubas), quando o mesmo faz uma breve reflexão sobre sua idade, as impressões paisagísticas possuem um caráter único em seu relato. Neste momento podemos dizer: o que ocorre é uma espécie de "transcendência da paisagem" (no sentido fenomenológico), evocada pelo fidalgo Brás Cubas. Acompanhemos.

Não falo dos anos. Não os sentia; acrescentarei até que os deitara fora, certo domingo, em que fui à missa na capela do Livramento. Como o Damasceno morava nos Cajueiros, eu acompanhava-os muitas vezes à missa. $O$ morro estava ainda nu de habitações, salvo o velho palacete do alto, onde era a capela (...) o morro era então desabitado ${ }^{31}$.

\footnotetext{
${ }^{23}$ Optou-se por esta obra por ser o escrito que traduz, de forma única na literatura brasileira, todo o pensamento de Machado de Assis. As Memórias mostra o quanto Machado de Assis soube filosofar e psicologizar o conhecimento humano. Do mesmo modo pode-se dizer que Machado de Assis através desta obra, principalmente, soube geografizar/geografar e temporalizar as relações humanas. - Algo que lembra Ratzel e Reclus. - Obra extremamente singular na literatura nacional. (Psicologizar e Geografizar ou Geografar, foram usadas aqui como palavras limites, algo estático sem intenção. Ou seja, Machado de Assis não demonstra ter intenção em desenvolver uma psicologia ou uma geografia, muito embora seja possível identificar essas características em alguns de seus escritos. Eis, portanto o sentido de tais termos aqui expressos, simplificadamente).

${ }^{24}$ SOUZA, Marquessuel Dantas de. Uma leitura da paisagem em Brás cubas e Quincas Borba de Machado de Assis: um olhar estético-geográfico sobre o Rio de Janeiro do século XIX. (Grifo do autor). 2014, p. 33. In: Linguagens. Acesso em 26 de maio de 2014.

${ }^{25}$ SOUZA, Marquessuel Dantas de. Geografia e Percepção: uma interpretação introdutória a partir da fenomenologia de Merleau-Ponty. 2012, p. 84.

${ }^{26}$ ASSIS, Machado de. Memórias Póstumas de Brás Cubas. 2012, p. 33.

${ }^{27}$ Idem, p. 61.

${ }^{28}$ SOUZA, Marquessuel Dantas de. Uma leitura da paisagem em Brás cubas e Quincas Borba de Machado de Assis: um olhar estético-geográfico sobre o Rio de Janeiro do século XIX. (Grifo do autor). 2014, p. 34. In: Linguagens. Acesso em 26 de maio de 2014.

${ }^{29}$ MONTEIRO, Carlos Augusto de Figueiredo. O Mapa e a Trama: ensaios sobre o conteúdo geográfico em criações romanescas. 2002, p. 128.
} 
Essa passagem nos mostra as transformações na paisagem. Quer dizer, quando o senhor Brás Cubas faz essa elucidação o mesmo nos transmite que na sua juventude, esta região ainda estava longe do modelo de cidade que era possível ver no centro da mesma. $\mathrm{Ou}$ seja, ou morros cariocas na ocasião ainda distanciavam da cidade em si. A vida nos morros era diferente quando observada do ponto de vista da modernização do centro da cidade do Rio de Janeiro. Fato fundamental para percebermos o quanto Machado de Assis detalhava suas descrições. "Em realidade, o autor defunto descreve uma paisagem com pouca interferência humana. Porém, com o passar dos anos a mesma região fora mudando de aspecto devido o crescimento da cidade" ${ }^{32}$. Vê-se, desde já, a ideia de natureza permeando os diálogos dos personagens da trama machadiana. A ação antrópica torna-se uma questão valiosa e muito importante a ser debatida pelos geógrafos que leiam a referida obra.

"Algumas outras passagens paisagísticas são citadas no romance, como por exemplo, a praia do Flamengo, Botafogo, a praia da Gamboa e outras" ${ }^{33}$. Neste momento há que observar a importância deste texto machadiano. Para tanto, apesar de sua ótica não direcionar-se para o estudo geográfico da natureza, mesmo assim é fundamental considerar suas breves descrições de ruas e outros invólucros da cidade do Rio de Janeiro imperial. Além disso, é notório colocar que nas $\mathrm{Me}$ mórias Machado de Assis faz questão de lembrar-se do ano de 1822: "data da nossa independência política"34. Acontecimento marcante para e na história do Brasil. Constituindo assim, uma rápida visão sobre a geografia política e a geopolítica do Brasil do século XIX.

\section{Paisagem, lugar e espaço: uma possível geografia fenomenológica}

A Geografia imanente contida nas entrelinhas das tramas de Machado de Assis nos fornece e nos propõe uma Geografia do Conhecimento embutida ou auxiliada pela linguagem literária. Com isso, um humanismo evidente em seus textos se apresenta de forma sutil diante de uma geograficidade com suas paisagens, lugares e espaços de uma região do império do Brasil (Rio de Janeiro). Assim sendo, as paisagens e os lugares indicam uma espacialidade e uma geograficidade que "estão ligadas à nossa existência"35. Algo identificável nos escritos machadianos, grosso modo, nos romances e contos, em especial. Identificação de uma geografia em que os relevos se mostram exuberantes ao olhar do geógrafo leitor da literatura nacional.

"A paisagem depende do ponto de vista" ${ }^{36}$ (ASSIS, 2010, p. 30) do sujeito presente no meio que o envolve, nos diz Machado de Assis. Conquanto que o mesmo saiba percebê-la em sua conjuntura. Com efeito, a percepção geográfica deste autor, sua ótica no invólucro do meio que o pertence o faz ultrapassar os limites de um literato. Por isso, estamos denominando Machado de Assis um Geógrafo Imanente. - Para Monteiro (2002), podemos considerar "os lugares como espelho" ${ }^{37}$. Assim sendo, os textos machadianos refletem o seu ambiente de vivência. Uma questão fenomenológica. O seu envoltório permeando todos os espaços que lhe diz respeito como Ser sensível e como Ente sensível (lembrando Heidegger e Merleau-Ponty).

Em se tratando de fenomenologia, cabe-nos uma indagação fundamentada na lógica da metodologia adotada no presente trabalho. Ou seja, em qual sentido relacionar noções de paisagem, lugar e espaço em Machado de Assis por um viés fenomenológico? Bem entendido, na Geografia de Machado de Assis, ou melhor, na leitura de algumas das obras machadianas, sejam estas romances ou contos, principalmente, podemos identificar o que Edward Relph chamou com propriedade de As bases fenomenológicas da Geografia. Pois que, para Relph "as bases fenomenológicas da realidade geográfica consistem de três pilares: de espaço, paisagens e lugares, na medida em que são diferentemente experienciados como atributos do mundo-vivi$\mathrm{do}^{\prime 38}$. Isto quer dizer exatamente que nas tramas machadianas estes três conceitos geográficos apontados por Relph são nítidos e evidentes. Isto é, enfatizando assim o valor do espaço geográfico, Machado de Assis fixa-se na ideia de paisagem da cidade do Rio de Janeiro no século XIX, assim como pluraliza a ideia de lugar e como um todo descreve a distribuição dos acontecimentos no e do espaço geográfico.

Neste contexto diz-se que a ideia de território, área, região, habitat, horizonte não são preocupações de Machado de Assis, ou melhor, na leitura de suas obras não identificamos a noção destas categorias geográficas. No entanto, as noções de paisagem, lugar e espaço são evidenciadas. Portanto, é neste sentido de apresentar a descrição paisagística, descrever o lugar intimamente relacionado e desvendar o lugar ampla-

\footnotetext{
${ }^{30}$ BARCELLOS, Frederico Roza. Espaço, Lugar e Literatura: o olhar geográfico machadiano sobre a cidade do Rio de Janeiro. 2009, p. 41. In: Espaço e Cultura. Acesso em 25 de junho de 2012.

${ }^{31}$ ASSIS, Machado de. Memórias Póstumas de Brás Cubas. 2012, pp. 160-161. Grifos nossos.

${ }^{32}$ SOUZA, Marquessuel Dantas de. Uma leitura da paisagem em Brás cubas e Quincas Borba de Machado de Assis: um olhar estético-geográfico sobre o Rio de Janeiro do século XIX. (Grifo do autor). 2014, p. 34. In: Linguagens. Acesso em 26 de maio de 2014.

${ }^{33}$ Idem, p. 35.

${ }^{34}$ ASSIS, Machado de. Memórias Póstumas de Brás Cubas. 2012, p. 43.

${ }^{35}$ MARANDOLA JR, Eduardo; GRATÃO, Lúcia Helena Batista. Geografia e Literatura: ensaios sobre geograficidade, poética e imaginação. 2010, p. 10

${ }^{36}$ ASSIS, Machado de. Quincas Borba. 2010, p. 30.

${ }^{37}$ MONTEIRO, Carlos Augusto de Figueiredo. 0 Mapa e a Trama: ensaios sobre o conteúdo geográfico em criações romanescas. 2002, p. 94.
} 
mente configurado (o espaço) com os personagens se deslocando intermitentemente, que podemos compreender uma geografia fenomenológica machadiana.

É nítido o mundo vivido que se passa em toda a trama romanesca do escritor Machado de Assis. Neste contexto, perguntemos: o que é o mundo vivido? É o lugar vivido, o lugar de vida, onde as coisas acontecem. Em outras palavras, "é o mundo onde estamos inseridos inegavelmente, por todas as nossas ações como ser existencial" ${ }^{39}$. Deveras, o que é a geograficidade, já referida e no qual se torna a base singular da fenomenologia machadiana? Com efeito,

\begin{abstract}
"Geograficidade refere-se às várias maneiras pelas quais sentimos e conhecemos ambientes em todas as suas formas, e refere-se ao relacionamento com os espaços e as paisagens, construídas e naturais, que são as bases e recursos das habilidades do homem e para as quais há uma fixação exis-

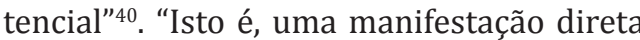
do ser na existência" ${ }^{41}$.
\end{abstract}

Certamente, a geograficidade é uma "relação existência do homem com o mundo" ${ }^{42}$. Doravante, poder-se-ia considerar: "a geografiacidade trata do conteúdo existencial do homem com o espaço terrestre" ${ }^{\prime 3}$. Por conseguinte, "ela coloca em questão a totalidade do ser humano, suas ligações existenciais com a Terra"44. Além disso, "cabe observar que a geograficidade, enquanto essência, define uma relação - a relação do ser-no-mundo" ${ }^{\prime 5}$. Em todo caso, essas definições estão presentes nos escritos de Machado de Assis.

Sem embargo, e em certo sentido, as descrições das narrativas se passam em sua maior parte no centro da cidade, ou nas proximidades (região central), como já referido. As ruas centrais são as referências básicas dos romances, em geral. Assim, percebe-se que a paisagem se inscreve de maneira particular entre uma esquina e outra.

A paisagem, o lugar e o espaço formam um élan forte e não se separam dentro da literatura de Machado de Assis. Apesar de serem conceitos dessemelhantes, por assim dizer, todos formam um único aparato da ge- ografia imanente de Machado de Assis.

Bem entendido, descrições de muitas ruas, praças e bairros são citados na maioria dos textos do autor em referência. Isto é corrente, especificamente nos romances e nos contos. De certo modo, os manuscritos estão repletos de descrições (breves), todavia, literariamente geográficas. Não obstante, lembremos que a dialética envolvendo Geografia e Literatura é de suma importância para compreendermos a "relação do ser ou do criador artístico com a experiência da narrativa dos lugares, com o mundo" 46 (SOUZA, 2013c, p. 105). Acrescentando diz-se: os textos machadianos constituem uma relação do homem com o meio que o envolve inegavelmente. Seu corpo, sua imaginação e seu Ser formam a unidade universal da totalidade de si mesmo.

\section{Considerações}

O que a obra machadiana nos revela é significante do ponto de vista cultural e contribui em muito para com os estudos geográficos, porém, temos que buscar o seu significado nas raízes de suas obras. Ou seja, devemos nos comportar em algum momento, a priori, como arqueólogos do saber para conseguirmos decifrar a anatomia, por assim dizer, de seus escritos. Contextualizar seus escritos é muito importante. Isto também é válido para autores brasileiros renomados tais como João Guimarães Rosa, Graciliano Ramos, Bernardo Guimarães, Euclides da Cunha, Manuel Antônio de Almeida, Joaquim Manuel de Macedo, apenas para citar alguns.

Consideramos que isto também é valioso não apenas nas análises dos romances, mas em abordagens de contos, poemas e, bem como de crônicas. Os escritos machadianos nos situam no tempo e no espaço no sentido de mapear uma região e nos mostra como as mudanças na geograficidade (no sentido de Dardel) e na temporalidade deixam resquícios de um passado que, grosso modo, ainda se mantém preservado. Ou seja, algumas ruas ou praças da cidade do Rio de Janeiro descritas ao longo dos textos ainda existem nos dias atuais. Principalmente aquelas localizadas no centro da cidade ou nas proximidades. 0 mesmo pode-se dizer de alguns

${ }^{38}$ RELPH, Edward C. As Bases Fenomenológicas da Geografia. In: Geografia, 1979, p. 18.

${ }^{39}$ SOUZA, Marquessuel Dantas de. Geografia e Fenomenologia: Merleau-Ponty e sua influência na Geografia Humana. 2013b, p. 271. In: Caminhos de Geografia. Acesso em: 03 de setembro de 2013.

${ }^{40}$ NOGUEIRA apud SOUZA, Marquessuel Dantas de. Geografia e Percepção: uma interpretação introdutória a partir da fenomenologia de Merleau-Ponty. 2012, pp. 51-52.

${ }^{41}$ SOUZA, Marquessuel Dantas de. Geografia e Percepção: uma interpretação introdutória a partir da fenomenologia de Merleau-Ponty. 2012, p. 71.

${ }^{42}$ NOGUEIRA apud SOUZA, Marquessuel Dantas de. Geografia e Percepção: uma interpretação introdutória a partir da fenomenologia de Merleau-Ponty. 2012, p. 51.

${ }^{43}$ HOLZER, Werther. Mundo e Lugar: ensaio de geografia fenomenológica. In: MARANDOLA JR, Eduardo; HOLZER, Werther; OLIVEIRA, Lívia de (Orgs). Qual o espaço do lugar? geografia, epistemologia, fenomenologia. 2012, p. 291.

${ }^{44}$ DARDEL, Eric. 0 homem e a terra: natureza da realidade geográfica. 2011, p. 31. No original francês: "Il met en cause la totalité de l'être humain, ses attaches existentielles avec la Terre". DARDEL, Eric. L'homme et la terre: Nature de la réalité Géographique. 1952 , p. 42.

${ }^{45}$ HOLZER, Werther. A geografia fenomenológica de Erica Dardel. In: DARDEL, Eric. 0 homem e a terra: natureza da realidade geográfica. 2011, p. 151.

${ }^{46}$ SOUZA, Marquessuel Dantas de. Geografia, Literatura e Música: o simbolismo geográfico na arte. In: Revista de Geografia. $2013 c$, p. 105. Acesso em: 17 de dezembro de 2013. 
bairros, igrejas e praias ou enseadas. 0 centro velho da cidade do Rio de Janeiro, principalmente, foi palco ou atelier para grandes obras no contexto da história do Brasil. - Salientamos que isto é digno sobre todos os sentidos na cultura do país.

Em todo caso, ao construir seus textos, Machado de Assis talvez não tivesse dado conta que houvera promovido um verdadeiro e riquíssimo estudo geográfico a cerca de seus personagens. Por conseguinte, acreditamos que a geografia que permeia os enredos não fora notado pelos críticos e literatos da época.

A pintura literária traçada por Machado de Assis ao longo de suas obras nos transmite uma capacidade outra e singular, no qual podemos chamá-lo com propriedade de o maior escritor brasileiro do século XIX. Portanto, somos orientados por exigência própria a dizer que Machado de Assis fora com mérito o Homero brasileiro, o Goethe do Brasil, o Wagner da literatura brasileira, o Shakespeare da América do Sul.

Talvez seja um abuso, mas já que estamos tratando de Geografia podemos chamá-lo de o Humboldt do Brasil. - Consideramos que Machado de Assis, no romance Memórias Póstumas de Brás Cuba ${ }^{47}$, principalmente, assim como em outros escritos, por exemplo, desenvolve uma poética da cidade. A imagem da cidade está presente em todo o texto deste romance. A delicadeza e a eloquência são formas outras que Machado de Assis utiliza para transmitir a sua percepção de mundo.

Ao falarmos da arte no âmbito da Geografia, acreditamos que este simples texto mostrou, sine qua non, ao menos em parte o valor da aproximação, ou melhor, a riqueza da relação entre Geografia e Literatura. Um olhar outro diante à realidade que nos faz sermos. 0 texto se apresentou como uma espécie de fenomenologia geográfica.

\section{Referências}

ANTONELLO, Ideni Terezinha. O olhar geográfico na interioridade do olhar sensível da obra literária. In: Simpósio Nacional sobre Geografia, Percepção e Cognição do Meio Ambiente (Homenageando Lívia de Oliveira) - UEL. Londrina, 2005. 16p. Disponível em: <http://geografiahumanista.files.wordpress.com/2009/11/ideni. pdf $>$. Acesso em 04 de agosto de 2012.

ASSIS, Machado de. Memórias Póstumas de Brás Cubas. 2aㅡ edição. 3aㅗ reimpressão. São Paulo: Martin Claret, 2012. 208p. (Coleção obra-prima de cada autor; 18)

Quincas Borba. 3a edição. 1' reimpressão. São Paulo: Martin Claret, 2010. 242p. (Coleção obra-prima de cada autor; 59)

BARCELLOS, Frederico Roza. Espaço, Lugar e Literatura: o olhar geográfico machadiano sobre a cidade do Rio de Janeiro. In: Espaço e Cultura. UERJ-NEPEC, RJ, no 25, pp. 41-52, Jan./Jun. de 2009. Disponível em: <http://www.e- -publicacoes.uerj.br/index.php/espacoecultura/article/ view/3562/2482>. Acesso em 25 de junho de 2012.

BASTIDE, Roger. Machado de Assis, paisagista. (Apresentação de Joaquim Alves de Aguiar). In: Revista USP. São Paulo, no 56, p. 192-202, dezembro/fevereiro, 2002-2003. Disponível em: <http://www.usp.br/revistausp/56/22-roger.pdf>. Acesso em 09 de setembro de 2013.

COSGROVE, Denis. A geografia está em toda parte: cultura e simbolismo nas paisagens humanas. In: CORRÊA, Roberto Lobato e ROSENDAHL, Zeny (Orgs). Paisagem, Tempo e Cultura. Rio de Janeiro: EdUERJ, 1998. pp. 92123. (Coleção Geografia Cultural)

DARDEL, Eric. 0 homem e a terra: natureza da realidade geográfica. (Trad. Werther Holzer) São Paulo: Perspectiva, 2011. 162p. (Estudos; 292)

L'homme et la terre: Nature de la réalité Géographique. Paris: Presses Universitaires de France (PUF), 1952. 136p.

HOLZER, Werther. Mundo e Lugar: ensaio de geografia fenomenológica. In: MARANDOLA JR, Eduardo; HOLZER, Werther; OLIVEIRA, Lívia de (Orgs). Qual o espaço do lugar? geografia, epistemologia, fenomenologia. São Paulo: Perspectiva, 2012. pp. 281-304. (Estudos: 302)

A geografia fenomenológica de Erica Dardel. In: DARDEL, Eric. 0 homem e a terra: natureza da realidade geográfica. Anexos. (Trad. Werther Holzer) São Paulo: Perspectiva, 2011. pp. 141-153. (Estudos; 292)

MARANDOLA JR, Eduardo; GRATÃO, Lúcia Helena Batista. Geograficidade, poética e imaginação. In: __ (Orgs). Geografia e Literatura: ensaios geograficidade, poética e imaginação. Londrina: EDUEL, 2010, pp. 07-15.

MONTEIRO, Carlos Augusto de Figueiredo. O Mapa e a Trama: ensaios sobre o conteúdo geográfico em criações romanescas. Florianópolis: Editora da UFSC, 2002. 242p.

RELPH, Edward C. As Bases Fenomenológicas da Geografia. In: Geografia, Rio Claro, v. 4, no 7, pp. 1-25, 1979.

SANTOS, Fabio Muruci dos. A Paisagem Oculta: desvelando o Rio de Janeiro do Quincas Borba de Machado de Assis. In: Revista Letras. Editora UFPR, Curitiba, no 60, pp. 176-201, jul./dez. 2003. Disponível em: <http://ojs.c3sl. ufpr.br/ojs/index.php/letras/article/view/2864/2346>. Acesso em 22 de junho de 2013.

SIMMEL, Georg. A Filosofia da Paisagem. (Traduzido por Artur Mourão). Universidade da Beira Interior. Portugal: Covilhã, 2009. (Coleção: Textos Clássicos de Filosofia). Disponível em: www.lusosofia.net. Acesso em 22 de junho de 2013.

SOUZA, Marquessuel Dantas de. Uma leitura da paisagem em Brás Cubas e Quincas Borba de Machado de Assis: um olhar estético-geográfico sobre o Rio de Janeiro do século XIX. In: Linguagens: Revista de Letras, Artes e Comunicação, Blumenau, v. 8, n. 1, pp. 28-38, jan./abr.

\footnotetext{
${ }^{47}$ Memórias Póstumas de Brás Cubas é considera a obra-prima de Machado de Assis. Apesar de ser um romance profundamente filosófico e psicológico, algo que o singulariza, esta obra máxima apresenta uma linguagem geográfica simples e ampla para abordar o Rio de Janeiro do século XIX.
} 
2014. Disponível em: <http://proxy.furb.br/ojs/index. php/linguagens/article/view/4074>. Acesso em $26 \mathrm{de}$ maio de 2014.

Geografia e Cultura: o espaço em prosa, mapa literário e imaginação. In: RA'E GA. Departamento de Geografia - UFPR, Curitiba, v. 28, pp. 242-253, 2013a. Disponível em: <http://ojs.c3sl.ufpr.br/ojs2/index.php/raega/ index>. Acesso em 11 de junho 2013.

Geografia e Fenomenologia: Merleau-Ponty e sua influência na Geografia Humana. In: Caminhos de Geografia. Uberlândia, v. 14, n. 46, pp. 265-272, Jun/2013b. Disponível em: < http://www.seer.ufu.br/index.php/ca- minhosdegeografia/article/view/17889/12825>. Acesso em: 03 de setembro de 2013.

. Geografia, Literatura e Música: o simbolismo geográfico na arte. In: Revista de Geografia (UFPE). Recife, vol. 30, no 1, pp. 103-147, 2013c. Disponível em: <http:// www.revista.ufpe.br/revistageografia/index.php/revista/article/view/667/480>. Acesso em: 17 de dezembro de 2013.

Geografia e Percepção: uma interpretação introdutória a partir da fenomenologia de Merleau-Ponty. São Paulo: Biblioteca 24 horas, 2012. 134p.

\title{
PHENOMENOLOGICAL GEOGRAPHY OF MACHADO DE ASSIS
}

\begin{abstract}
This paper provides a brief analysis of the Phenomenological Geography found in the writings of Machado de Assis, evidencing a possible reading of the landscape of the city of Rio de Janeiro in the nineteenth century. In addition, the paper investigates the idea of place and space in the plots of Machado de Assis's fictional works. These concepts prove essential within the context of geography, enabling the identification of Machado de Assis as an immanent urban geographer. Even though the landscape, the place and the space transcend the characters in their everyday relationships in urban spaces, a background geographicity permeates Machado de Assis's plots.
\end{abstract}

Keywords: Geography; Machado de Assis; Phenomenology.

\section{LA GEÓGRAPHIE PHNONOLÓGIQUE DE MACHADO DE ASSIS}

\begin{abstract}
Resumé: Cet article cherche à faire une brève analyse de la géographie phénoménologique présente dans les écrits de Machado de Assis. Il essaie aussi de montrer la possibilité de lire le paysage de la ville de Rio de Janeiro au XIXe siècle, ainsi que l'idée de lieu et d'espace chez Machado. Ces concepts sont essentiels dans le contexte de la Géographie; en outre, ils nous permettent de voir Machado de Assis comme um immanent géographe urbain,. Bien que le paysage, le lieu et l'espace peuvent transcender les personnages dans leurs rapports quotidiennes, on peut voir un fond de géographicité imprégnant les trames machadiennes Mots-clés : Geógraphie, Machado de Assis, Phénomenologie.
\end{abstract}

